\title{
A criança fala: o desenho como fonte de escuta e produção artística sobre as brincadeiras preferidas no cotidiano da educação infantil
}

\author{
The child speaks: \\ the drawing as source of listening and artistic production about their \\ favorite play in the school routine of children's education
}

\section{La infancia habla: el dibujo como fuente de escucha y producción artística sobre los juegos preferidos en el cotidiano de la educación infantil}

\author{
Aline Patricia C. Tolentino de Lima' \\ https://orcid.org/0000-0002-6834-7209 \\ Evani Andreatta Amaral Camargo² \\ https://orcid.org/0000-0002-8952-4796
}

\begin{abstract}
Resumo: Este artigo apresenta uma discussão sobre a importância da escuta atenta das crianças em pesquisas e o desenho como fonte de produção artística sobre as brincadeiras preferidas no cotidiano da Educação Infantil. O objetivo deste estudo é apresentar produções de desenhos realizados pelas crianças para representar suas brincadeiras preferidas e discutir a importância do brincar para o desenvolvimento infantil, por meio da fundamentação teórica da psicologia histórico-cultural. A metodologia utilizada foi a pesquisa qualitativa ancorada na abordagem histórico-cultural. Foram realizadas rodas de conversa e registros de desenhos produzidos pelas crianças sobre suas brincadeiras preferidas. Como resultado, foi possível ampliar os conceitos sobre a participação da criança na educação infantil, analisados a partir da opinião da criança e não apenas do adulto, propiciando ainda às pesquisadoras uma reflexão sobre os espaços e tempos destinados ao brincar no cotidiano da Educação Infantil.
\end{abstract}

Palavras-chave: Desenho. Brincadeiras. Educação Infantil.

Abstract: This article presents a discussion on the importance of careful listening to children in research and the drawing as source of artistic production about their favorite play in the school routine of Children's Education. The aim of this study is to present production of drawings made by children to represent their favorite play and

\footnotetext{
'Doutoranda em educação (USP) e Mestra em Educação (CUML). Chefe da Seção de Pré-escolas (Secretaria Municipal de Educação de Ribeirão Preto). E-mail: alinepctolentino@hotmail.com
}

${ }^{2}$ Doutora em educação pela Universidade Estadual de Campinas (UNICAMP). Aposentada. E-mail: evaniamaral@gmail.com

Olhar de professor, Ponta Grossa, v. 24, p. I-22, e-17637.08I, 202 I.

Disponível em <https://revistas2.uepg.br/index.php/olhardeprofessor> 
discuss the importance of the play for the children's development through theoretical foundation of historicalcultural psychology. The methodology used was qualitative research based on historical-cultural approach, chat groups were conducted and registers of the drawings made by the children about their favorite play were made. As a result, it was possible to widen concepts about the participation of the child in Children's Education, which were analyzed based on the opinions of both the children and the adults, making it possible for the researchers to reflect on the spaces and moments dedicated to the play in the school routine of Children's Education.

Keywords: Drawing. Play. Children's Education.

Resumen: Este artículo presenta una discusión sobre la importancia de la escucha atenta de los niños en investigaciones y el dibujo como fuente de producción artística sobre los juegos preferidos en el cotidiano de la Educación Infantil. El objetivo de este estudio es presentar producciones de dibujos realizados por los niños para representar los juegos preferidos y discutir la importancia de jugar para el desarrollo infantil por medio de la fundamentación teórica de la psicología histórico-cultural. La metodología utilizada fue la investigación cualitativa anclada en el abordaje histórico-cultural, fueron realizados círculos de conversación y registros de dibujos producidos por los niños sobre sus juegos preferidos. Como resultado, fue posible ampliar los conceptos sobre la participación del niño en la educación infantil, analizados a partir de la opinión del niño y no solo del adulto, brindando además a las investigadoras una reflexión sobre los espacios y tiempos destinados al juego en el cotidiano de la Educación Infantil.

Palabras clave: Dibujo. Juegos. Educación Infantil.

\section{Introdução}

Este trabalho partiu da observação e reflexão de uma das autoras, que vivenciando o cotidiano na Educação Infantil durante a pesquisa de campo, percebeu a importância do desenho como uma linguagem da criança para se expressar e da necessidade do brincar como atividade principal, que contribuem significativamente para o seu desenvolvimento pleno.

Um dos objetivos principais desta pesquisa é dar voz às crianças, ancorado no paradigma da infância, que as compreende como seres atuantes e sujeitos de direitos, tendo como fundamento a pressuposição de que a participação infantil é uma questão social, política e científica.

O brincar é essencialmente um direito de liberdade da criança que é reconhecida como pessoa com interesses, desejos e vontades muito singulares. Por isso, deve ser garantido, já que é sua realidade, bem como um elemento indispensável para que ela se desenvolva de forma plena e saudável. O brincar é a manifestação da liberdade da criança e é reconhecido como um direito porque somente ela pode exercê-lo por si contando com o apoio, respeito e o estímulo do adulto (FRANCO, 2008, p. I47).

A pesquisa foi fundamentada na abordagem histórico-cultural. Como o tema principal deste estudo é o brincar, foi possível, por meio do aprofundamento teórico dessa abordagem, analisar uma outra maneira de ver a criança em seu processo de aprendizagem e desenvolvimento. Por isso, a ênfase está em ouvir o que as crianças têm a nos dizer, pois são as maiores interessadas neste processo de desenvolvimento, em que devem ser consideradas como capazes e participativas de suas aprendizagens. E, desta maneira, a pesquisadora buscou construir um espaço (intencional) para a participação da criança no cotidiano da escola de Educação Infantil.

Olhar de professor, Ponta Grossa, v. 24, p. I-22, e-17637.08I, 2021.

Disponível em <https://revistas2.uepg.br/index.php/olhardeprofessor> 
Este estudo buscou identificar quais são as preferências das crianças em relação às brincadeiras, em uma instituição de Educação Infantil de rede pública, por meio da escuta atenta de diferentes linguagens. Teve como objetivos específicos, identificar, do ponto de vista das crianças, quais brincadeiras fazem parte do cotidiano da instituição, analisar as diferentes linguagens como produção artística e como forma de expressar as suas escolhas sobre o brincar.

Foi realizada uma revisão de literatura em relação ao estado da arte sobre pesquisas que tenham como temática o desenho infantil e como fundamentação teórica a abordagem históricocultural para ampliar as discussões teóricas deste artigo. Ferreira (1998) fez uma pesquisa de campo com análises de desenhos infantis, em que seu olhar diferenciado se voltou para o processo de desenvolvimento dos desenhos, sua criação e interpretação das figuras e não para os produtos finalizados, ressaltando a importância da linguagem verbal no processo de produção do desenho infantil.

Silva (2002) também fez um estudo sobre o desenho da criança concebido como um processo, que consiste em uma produção gráfica e estética, uma esfera de atividade infantil, socialmente constituída, afirmando após análise dos dados de sua pesquisa e discussão teórica que "é importante destacar que, no processo de constituição de uma determinada ação, ocorre uma elaboração por parte do sujeito e não uma simples cópia do funcionamento externo" (SILVA, 2002, p.25).

A revisão de literatura contribuiu para a ampliação da discussão deste artigo e, a partir das análises das pesquisas realizadas pelas autoras citadas, foi possível compreender que o desenho infantil é uma linguagem específica da criança, é constituído socialmente e deve ser observado em seu processo de elaboração, associando-o à linguagem oral para compreender o significado que a criança atribui aos seus desenhos, sendo um campo de estudo importante para analisarmos as especificidades a respeito do desenvolvimento infantil.

Neste texto, foi feito um recorte da pesquisa, apresentando algumas produções de desenhos realizadas pelas crianças, para expressar a brincadeira preferida de cada uma, buscando identificar, pela linguagem do desenho em sua representação gráfica, a compreensão das brincadeiras escolhidas e discutidas entre as crianças e a pesquisadora, após as brincadeiras terem sido realizadas, respeitando, assim, as especificidades da infância.

O artigo está estruturado e organizado a partir da introdução; metodologia da pesquisa; da discussão teórica, subdivida em tópicos que abordam os estudos do desenho como uma produção artística da criança, a imaginação na infância e a importância do brincar de faz de conta no cotidiano da Educação Infantil. Após a discussão teórica são apresentados e analisados os dados da pesquisa em relação à produção de desenhos e, finalmente, as conclusões que apontam o desenho infantil como uma produção artística da criança e forma de escuta no cotidiano da Educação Infantil.

Olhar de professor, Ponta Grossa, v. 24, p. I-22, e-17637.08I, 2021.

Disponível em <https://revistas2.uepg.br/index.php/olhardeprofessor> 
A criança fala: o desenho como fonte de escuta e produção artística sobre as brincadeiras...

\section{Metodologia da pesquisa}

$\mathrm{Na}$ pesquisa qualitativa é considerada a questão da importância da fidelidade aos sujeitos e pesquisador (MINAYO, 20I2), sendo que toda compreensão é parcial e inacabada, tanto a do entrevistado, que tem um entendimento contingente e incompleto de sua vida e de seu mundo, como a dos pesquisadores, que também estão limitados ao que compreendem e interpretam.

Este estudo, de cunho qualitativo, baseou-se na observação participante para a realização dos trabalhos de campo, a partir de diferentes perspectivas (objetivas, subjetivas e interpretativas). A pesquisa de campo foi realizada com uma turma de vinte e um alunos, na faixa etária de quatro a cinco anos, que frequentavam a Educação Infantil na rede pública municipal, em uma escola localizada no interior de São Paulo.

Para o levantamento de dados, primeiramente foi encaminhado $\circ$ projeto de pesquisa ao Comitê de Ética em Pesquisa com Seres Humanos da Plataforma Brasil, que foi aprovado pelo Parecer de número: 2.735 .555 .

Depois do projeto de pesquisa ter sido aprovado, foi marcada uma reunião com a gestora da instituição escolhida para poder dar início à pesquisa de campo. Foram também solicitadas as autorizações dos responsáveis em uma reunião junto à pesquisadora e à gestora, expondo o contexto da pesquisa e, após isso, com as crianças que foram autorizadas a participar, foi apresentado o termo de assentimento, com uma linguagem acessível à criança, explicitando como a pesquisa seria realizada e qual seu objetivo. Com a ajuda da pesquisadora, as crianças registraram o seu primeiro nome ou optaram pelo registro em desenho. E apenas após o termo de autorização dos responsáveis e do termo de assentimento serem analisados e assinados, o levantamento dos dados foi feito com as crianças que aceitaram o convite.

As fontes de pesquisa utilizadas, portanto, foram: as entrevistas com as crianças, as rodas de conversas, as brincadeiras e os desenhos elaborados pelas crianças que expressaram suas opiniões sobre o brincar e brincaram em diferentes ocasiões, dentro da rotina escolar. Como forma de registro dessas interações, a pesquisadora fez um diário de campo com as anotações diárias, registros por meio de fotos, áudios das entrevistas individuais e rodas de conversa e registros das produções dos desenhos das crianças, que escolheram nomes fictícios para identificar suas participações.

A pesquisa teve como intuito investigar a visão do brincar do ponto de vista infantil. Para tanto, foi necessário construir com as crianças um espaço que lhes permitisse manifestar suas ideias de modo organizado, respeitando as características e particularidades do mundo da infância, possibilitando discussões, reflexões e encaminhamentos. Desta maneira, tomou-se como inspiração a abordagem

Olhar de professor, Ponta Grossa, v. 24, p. I-22, e-17637.08I, 2021.

Disponível em <https://revistas2.uepg.br/index.php/olhardeprofessor> 
educativa italiana ${ }^{3}$ (EDWARDS, GANDINI, FORMAN, 2016), Reggio Emília, que apesar de não ser uma abordagem metodológica, busca em suas práticas pedagógicas, a escuta atenta das crianças.

Sobre essa abordagem educativa italiana, a mesma tem sido uma referência para a Educação Infantil atualmente, e serviu de inspiração para um dos objetivos da pesquisa de campo, que é a escuta atenta das crianças por meio de rodas de conversa e de decisões coletivas a respeito das brincadeiras preferidas da turma.

Em seu artigo, Andries (2016) descreve sobre as escolas italianas de Reggio Emília que vem sendo evidenciadas pela forma que atuam na Educação Infantil. A autora foi conhecer as escolas pessoalmente, buscando refletir sobre a linguagem musical, como ela se configura nessa abordagem educativa e descreveu algumas das ferramentas pedagógicas que são utilizadas nas referidas escolas infantis italianas para a escuta atenta das crianças.

Como reflexão desta leitura, uma das inspirações para tal pesquisa foi incorporar, da proposta de abordagem educativa italiana, a ferramenta de assembleia. Os projetos partem do interesse das crianças, que trabalham em pequenos grupos, geralmente com seis crianças, em pequenos projetos de pesquisa, e posteriormente é realizada uma grande assembleia, em que cada uma coloca suas experiências e vivências, e juntas tomam decisões.

Neste trabalho, foram utilizadas, assim como na abordagem educativa italiana, as assembleias para ouvir o que as crianças têm a dizer sobre o brincar, e também para decidir quais brincadeiras são as preferidas da turma, procurando compreender a brincadeira sob o olhar da criança. Como pontuado anteriormente, as crianças devem ser ouvidas porque são capazes e participativas em seu processo de aprendizagem. Os principais questionamentos realizados foram: Quais eram as brincadeiras preferidas? Quais brincadeiras conheciam e como eram? Quais aconteciam em casa e na escola?

A observação ocorreu em um primeiro momento com as entrevistas individuais. Após a realização das mesmas, foi feita uma análise à luz da fundamentação teórica escolhida, possibilitando a reflexão da professora pesquisadora sobre a importância do brincar no cotidiano da Educação Infantil. Posteriormente, ocorreram cinco rodas de conversas, cuja discussão principal era a brincadeira preferida da turma. Na última roda, foi realizada uma votação, por meio de desenhos, sobre qual era a brincadeira preferida do grupo. Após a pesquisadora apurar os votos, a brincadeira eleita foi vivenciada por todos. Também quanto à observação participante, a pesquisadora fez registros no diário de campo e registros fotográficos em momentos em que a brincadeira simbólica acontecia entre as crianças no cotidiano da instituição de Educação Infantil.

\footnotetext{
${ }^{3} \mathrm{O}$ termo que este estudo apresenta como abordagem educativa italiana refere-se um conjunto de escolas de Educação Infantil criadas nos últimos trinta anos na cidade de Reggio Emília, que fica localizada ao norte da Itália.
} 
A criança fala: o desenho como fonte de escuta e produção artística sobre as brincadeiras...

Para esse artigo serão apresentadas algumas produções de desenhos feitas pelas crianças após as discussões nas rodas de conversas, para representar suas brincadeiras preferidas, como fonte de produção artística e escuta.

\section{Discussão teórica sobre o desenho como produção artística da criança, imaginação e a importância do brincar de faz de conta no cotidiano da educação infantil}

O desenho como produção artística da criança

É preciso, antes de tudo, romper com o olhar adultocêntrico que foi construído historicamente e acabou silenciando as infâncias (SILVA; SOUZA E OLIVEIRA, 20I8). É preciso que realmente se escutem as vozes das crianças pequenas que fazem parte do cotidiano da Educação Infantil.

A infância, enquanto categoria social, carrega uma marca histórica de silenciamento e ausência da identidade da criança, mas se faz necessário que em tempos atuais, pesquisadores no âmbito escolar e docentes rompam com essas práticas que silenciam as vozes das crianças, trazendo à tona suas posições.

A autora Demartini (2007) ressalta a importância que cada vez mais, em tempos atuais, pesquisadores e professores aprendam a ouvir as crianças e jovens e, nesse processo, se atentem que existem crianças que falam e também as crianças que não falam. Cabe ao pesquisador ter esse olhar atento às diferentes formas de manifestação da criança que demandam suas histórias de vida e seu contexto, compreendendo que, de alguma forma expressiva, todas as crianças falam.

Este estudo buscou contemplar de maneira mais ampla as diferentes linguagens da criança como a oralidade, o desenho e o momento do jogo simbólico, para compreender as particularidades do mundo infantil, rompendo com o olhar adultocêntrico.

A teoria histórico-cultural possibilita uma crítica e superação das concepções maturacionistas a respeito do desenho infantil, porque permite ver o desenho como um signo empregado pelo homem e constituído a partir das suas interações sociais (SILVA, 1998).

Desenhar é exatamente a criação típica da primeira infância, principalmente do período préescolar (VIGOTSKI, 2009). Nessa idade, o desenho é uma das atividades preferidas da criança e possibilita a ela se expressar com mais facilidade. Para que a criança recrie algo de maneira nova no ato de desenhar e verbalizar o que está desenhando, é preciso que tenha vivências e experiências pessoais e a habilidade de analisar as relações sociais entre as pessoas, em diferentes ambientes. Vigotski (2009) aponta como um acúmulo de experiências anteriores para recriar algo.

Notamos que, quando uma criança libera seus repositórios de memória através do desenho, ela o faz à maneira da fala, contando uma história. A principal característica

Olhar de professor, Ponta Grossa, v. 24, p. I-22, e-17637.08I, 2021.

Disponível em <https://revistas2.uepg.br/index.php/olhardeprofessor> 
dessa atitude é que ela contém certo grau de abstração, aliás, necessariamente imposta por qualquer representação verbal (VIGOTSKI, 2007, p. 136).

Há um momento crítico (VIGOTSKI, 2007) em que a criança descobre que os traços feitos por ela podem significar algo e, então, os desenhos representam um signo da linguagem verbal, acompanhando a linguagem falada pela criança. A fala organiza o desenho; por isso, quando a criança desenha e diz em voz alta o que irá desenhar, a linguagem é um recurso mediador que orienta e dá sentido ao desenho.

Quando o adulto questiona a criança sobre sua produção gráfica (SILVA, 1998), leva a criança a pensar sobre sua produção e sobre o desenho como um signo gráfico. Pela linguagem oral, a criança verbaliza o que desenhou ou está desenhando, e muitos detalhes sobre o desenho só podem ser decifrados pela oralidade da criança que produziu aquele desenho.

Vigotski (2007) avalia que a criança não se preocupa com a representação da realidade, com a reprodução daquilo que vê, mas por meio do desenho tenta indicar aspectos de determinados objetos, desenha aquilo que sabe sobre os objetos. As ideias de Vigotski contribuem para que possamos compreender que:

[...] não se trata de aprender a desenhar relendo ou copiando modelos de imagens da arte, ou seguindo passos impostos pelo professor para aprender a fazer determinados desenhos, mas de assimilá-los aos próprios esquemas desenhistas, no contato com os códigos da linguagem, gerados nas diferentes culturas e épocas, em sua abertura à singularidade dos desenhistas individuais, que desenvolvem seus percursos de criação pessoal, agora informados pelas culturas (IAVELBERG, 20I3, p.25).

"O desenho transforma-se efetivamente em representação simbólica quando a nomeação passa a se dar no início do ato de desenhar e a criança torna-se capaz de decidir antecipadamente o que vai desenhar" (FONTANA, CRUZ, 1997, p.146).

O desenho infantil pode ser considerado como uma fonte de expressão artística da criança, pois, de acordo com a psicologia histórico-cultural (VIGOTSKI, 2009), ela vai se apropriando de sua cultura e signos que foram historicamente construídos pelo homem e passa a representar, por meio da linguagem do desenho, que também é um signo da humanidade, o que antecede o desenvolvimento da linguagem escrita.

Em algumas abordagens maturacionistas, o desenho é colocado como algo natural e espontâneo, divergindo do conceito de desenho que a abordagem histórico-cultural define, que é o desenho ser constituído socialmente, pois a criança é um ser social e suas produções a refletem a partir de suas relações sociais e vivências. A criança desenha porque vive em uma cultura em que a atividade gráfica é uma das formas de expressão. 
A criança fala: o desenho como fonte de escuta e produção artística sobre as brincadeiras...

O desenho infantil é compreendido à luz da perspectiva histórico-cultural em psicologia, como forma de linguagem na qual se expressa e constitui a imaginação criadora do ser humano (NATIVIDADE, COUTINHO, ZANELLA, 2008). O desenho pertence ao universo infantil como uma linguagem específica na infância que expressa vivências, ideias, vontades e emoções das crianças.

O desenho da criança expressa significados compartilhados socialmente, aos quais ela atribui sentidos, que só podem ser compreendidos por meio das explicações da criança sobre o que produziu.

Imaginação na infância

Para compreender melhor $\circ$ momento do brincar e do desenhar, contribuindo para $\circ$ desenvolvimento da psique infantil, é preciso analisar como a imaginação se constitui na infância. Para isso, foi estudada a publicação de Vigotski (2009): “Imaginação e criação na infância”, traduzido por Zoia Prestes e apresentado por Ana Luiza Smolka.

Este ensaio psicológico foi publicado pela primeira vez em russo em 1930, com base em notas de uma série de palestras feitas para pais e professores, nas quais Vigotski enfoca e analisa a imaginação como uma formação especificamente humana, relacionada à atividade criadora do homem.

A preocupação de Vigotski (MOURA et al., 2016) era mostrar a importância do trabalho pedagógico na criação de condições e na abertura de novas formas de participação das crianças na cultura em que estavam inseridas, lembrando que o desenvolvimento da criança está relacionado com a apropriação da cultura.

O conceito de atividade que Vigotski (MOURA et al., 2016) aborda está ancorado no materialismo histórico-dialético de Karl Marx e tem relação com as bases materiais de existência e com a atividade especificamente humana, mediada na apropriação dos instrumentos e signos. A apropriação e adequação à cultura em que o sujeito está inserido estão relacionadas à capacidade que o cérebro humano tem da plasticidade cerebral, que é a propriedade de uma substância que permite que ela seja alterada e conserve as marcas desta alteração.

Nosso cérebro e nossos nervos, que possuem uma enorme plasticidade, modificando com facilidade sua estrutura mais tênue sob diferentes influências e, se os estímulos são suficientemente fortes ou repetidos com bastante frequência, conservam as marcas dessas modificações (VIGOTSKI, 2009, p. 12).

A imaginação, que é a base criadora de toda atividade humana, só é possível devido ao fato de o cérebro humano não ser um órgão que apenas conserva o que foi apreendido e o reproduz, mas que tem a capacidade de também combinar e reelaborar por meio da criação, sendo que a imaginação surge devido às experiências e atividades vivenciadas anteriormente.

Olhar de professor, Ponta Grossa, v. 24, p. I-22, e-I7637.08I, 2021.

Disponível em <https://revistas2.uepg.br/index.php/olhardeprofessor> 
Esses processos de criação surgem na infância pelas brincadeiras e pelos desenhos, nos quais a criança se coloca no lugar do outro, utilizando sua imaginação, interpretando papéis sociais; assim como objetos também são colocados em funções de outros objetos. Quando a criança brinca de imitar, ela não está apenas reproduzindo uma experiência vivenciada, mas também reelaborando situações de forma criativa.

A abordagem histórico-cultural considera a atividade lúdica a principal atividade no desenvolvimento infantil. $\mathrm{Na}$ atividade lúdica, a criança desenvolve sua capacidade imaginativa que, de acordo com Vigotski (2010), não é inata, mas resulta da cultura em que a criança está inserida e de suas experiências, podendo se constituir e desenvolver também por meio da literatura infantil, desenhos, pinturas, brincadeiras e vivências de seu contexto histórico.

A estética do desenho infantil, segundo Vigotski (2009), refere-se ao estudo das condições de produção e efeitos da criação gráfico-plástica infantil, um campo de estudo que investiga as condições materiais de produção do grafismo infantil e compreende o psiquismo da reação estética que é, para a criança, o desenvolvimento de sua atividade criadora por meio da função psíquica superior da imaginação.

A criança nasce imersa em uma cultura e ao longo do seu desenvolvimento vai se apropriando dos instrumentos e signos desta cultura. De acordo com a teoria histórico-cultural, consideramos instrumento tudo aquilo que o homem utiliza como ferramenta para auxiliá-lo em determinada função específica, por exemplo, o lápis e o papel são ferramentas muitos utilizadas atualmente pelo homem e pela criança, que inserida neste contexto cultural, vai atribuindo significação a esses instrumentos que fazem parte do seu cotidiano e que servem para registrar algo.

A criança, nesse processo, se apropria do conhecimento e das propriedades desses instrumentos, por meio da observação dos modos de agir com os objetos de outros representantes mais experientes da cultura e também mediante instruções explícitas de como utilizá-los. Esse processo de interação com o outro e com o meio é definido por Vigotski (2010) como mediação.

Em sua obra, Vigotski (2009) aborda o desenho infantil como uma representação do conhecimento da criança e como a constituição social de uma importante função psíquica cultural, a imaginação criadora, cujo objeto de estudo é o grafismo infantil e a relação entre a imaginação criadora e a criação artística geral da criança.

Nesse sentido, considera-se o desenho enquanto uma expressão observável da imaginação criadora humana da criança que representa o universo infantil constituído a partir de seu contexto cultural.

Olhar de professor, Ponta Grossa, v. 24, p. I-22, e-17637.08I, 2021.

Disponível em <https://revistas2.uepg.br/index.php/olhardeprofessor> 
A criança fala: o desenho como fonte de escuta e produção artística sobre as brincadeiras...

Pode-se concluir que se $\circ$ ato de imaginar está relacionado às vivências e experiências anteriormente compartilhadas pelas crianças, quanto mais experiências e vivências a criança tiver, mais terá possibilidades em desenvolver sua criatividade.

Para desenvolver a atividade criadora como Vigostki (2009) coloca, não são apenas as experiências próprias que contam, mas também as inúmeras representações historicamente construídas pelo outro que também interferem na atividade criadora da criança.

\section{Importância do brincar de faz de conta no cotidiano da Educação Infantil}

É importante esclarecer que a brincadeira, sendo atividade principal da criança, não é uma atividade instintiva, mas sim objetiva, que surge das percepções que ela tem da cultura.

A criança, como ser capaz, na fase de infância, quer agir com o seu próprio "eu", quer dirigir o carro do pai, fazer comida como a mãe; no entanto, ainda não pode porque falta amadurecimento para se apropriar e dominar essas ações objetivas. Para satisfazer essa necessidade de agir com seu próprio "eu”; a criança, na atividade lúdica, no jogo de interpretações, consegue efetivar tais vontades tendo autonomia para realizar as mesmas atividades dos adultos ao seu redor. Essa fase da infância é marcada pela necessidade que a criança tem de agir como o adulto (VIGOTSKI, 20I0).

É durante este período do desenvolvimento infantil que é criada a clássica fórmula
"eu mesmo"; com o emprego do "eu mesmo" dito pela criança, esta converte o
modo adulto de ação em conteúdo de sua própria ação; agindo como uma pessoa
em relação ao objeto, ela torna-se consciente dele como um objeto humano. "Me
deixa" é a fórmula que expressa a essência real da situação psicológica na qual uma
criança se encontra no limiar deste novo estágio em seu desenvolvimento - no limiar
do período pré-escolar (VIGOTSKII, 20I0, p. I2I).

O papel dominante do brinquedo na infância como uma atividade lúdica, que faz parte de um jogo, contribui significativamente para o desenvolvimento psíquico da criança. Quando Leontiev (2010) coloca a brincadeira como atividade principal não está dando ênfase ao tempo que a criança brinca, mas sim porque na atividade do brincar ocorrem as mais importantes mudanças no desenvolvimento psíquico dela, é um caminho de transição para um novo e mais elevado nível de desenvolvimento.

A ação do brincar está relacionada com a possibilidade da imaginação, mas não se pode esquecer que ao brincar a criança está reproduzindo ações com as quais convive em sua cultura, então o brincar não provém da situação imaginária inata, mas sim, inicialmente, da necessidade de agir como o adulto e, nesse processo, se faz necessária a imaginação criativa.

Quando a criança, ao interpretar um papel social por meio de sua imaginação, cria uma forma de jogo teatral, que seria quando esta atribui o papel principal para si mesma, por exemplo, quando brinca de escolinha e interpreta a professora, ela representa um papel no jogo teatral da ação real 
vivenciada, que através da imaginação se faz possível, mas essa ação e interpretação é um jogo teatral regido pelas regras da ação real do papel da professora (ELKONIN, 2009).

O brincar não pode ser considerado como uma atividade principal para a criança apenas porque ela sente prazer ao brincar, nessa fase da infância existem outras experiências que são mais prazerosas do que o brincar, como por exemplo "chupar chupeta” (VIGOSTKI, 2007), mas porque o brinquedo está relacionado com a necessidade que a criança tem de agir como o adulto, existe uma satisfação quando ela se sente capaz, por meio da situação imaginária, de realizar a ação que o adulto faz, que na vida real ainda não consegue realizar, mas na brincadeira, por meio da imaginação, consegue.

Como se pode ver, a situação imaginária só é possível a partir das vivências e experiências que a criança tem. Na situação que se acabou de descrever acima, em que a criança ao brincar se coloca no lugar do outro, satisfazendo uma vontade de agir como o adulto, pode-se dizer que o brinquedo atua na zona de desenvolvimento proximal.

[...]o brinquedo cria uma zona de desenvolvimento proximal da criança. No brinquedo, a criança sempre se comporta além do comportamento habitual de sua idade, além de seu comportamento diário, no brinquedo, é como se ela fosse maior do que é na realidade. Como no foco de uma lente de aumento, o brinquedo contém todas as tendências do desenvolvimento sob a forma condensada, sendo, ele mesmo, uma grande fonte de desenvolvimento (VIGOSTSKI, 2007, p. 122).

O conceito de zona de desenvolvimento proximal se refere justamente ao momento de aprendizagem da criança, que fica entre o que a criança já consegue fazer com autonomia, e o que ela ainda não consegue, mas com a ajuda de um elemento secundário como o brinquedo ou o adulto, realiza, progredindo assim em seu desenvolvimento de forma significativa.

Ao brincar, a criança estabelece certas regras, e por mais simples que seja a brincadeira, está relacionada ao contexto da criança, por isso o jogo do brincar envolve regras. Por exemplo, a criança, ao imitar a professora em sua situação imaginária, estabelece regras de comportamento, pois na brincadeira ela age da mesma forma que o seu personagem age na vida real. $E$ ao estabelecer regras nas brincadeiras, principalmente de interpretação de papéis sociais, a criança desenvolve sua moralidade, aprendendo as regras de convivência no meio social (ELKONIN, 2009).

Como dito anteriormente, Vigotski trabalhou com um domínio da atividade que tem uma profunda relação com o desenvolvimento da criança, o brinquedo. Em suas palavras,

O brinquedo aparece na criança em idade pré-escolar. Ela surge a partir de sua necessidade de agir em relação não apenas ao mundo dos objetos diretamente acessíveis a ela, mas também em relação ao mundo mais amplo dos adultos. Uma necessidade de agir como um adulto surge na criança, isto é, de agir da maneira que ela vê os outros agirem, da maneira que lhe disseram, e assim por diante (VIGOTSKI, 2010, p. 125).

Olhar de professor, Ponta Grossa, v. 24, p. I-22, e-17637.08I, 2021.

Disponível em <https://revistas2.uepg.br/index.php/olhardeprofessor> 
A criança fala: o desenho como fonte de escuta e produção artística sobre as brincadeiras...

A criança vai reproduzir aquilo que ela vê ou é feito; dessa forma, ela aprende com o externo, sendo o processo de aprendizagem um processo de reprodução, o que está diretamente ligado com o seu contexto.

Para compreender o papel dos jogos simbólicos nas brincadeiras, como contribuição ao que está sendo discutido, serão apresentados os jogos protagonizados ${ }^{4}$, descritos pelo autor Elkonin (2009), que se fundamentou na teoria histórico-cultural, o que auxilia a compreender melhor como a brincadeira acontece.

No jogo de papéis, a criança consegue satisfazer seus desejos de conviver com o adulto, reproduzindo suas ações de forma lúdica. A atividade lúdica tem um caráter simbólico, e ela só acontece quando a criança realiza uma ação ou manipula um objeto subtendendo outro.

É considerado conteúdo do jogo o que a criança destaca como aspecto principal nas atividades do adulto. $\mathrm{Na}$ idade pré-escolar, os conteúdos dos jogos são especificamente as ações com os objetos.

É importante ressaltar que as crianças de três a quatro anos permanecem no jogo por dez a quinze minutos, já na faixa etária de quatro a cinco anos, permanecem no jogo durante quarenta a cinquenta minutos.

As crianças menores na Educação Infantil realizam o jogo de acordo com o objeto que possuem, baseando-se nas relações humanas, ou seja, uma reprodução de seu cotidiano, em que o principal são as próprias relações. Já as crianças com idade entre quatro e cinco anos têm o foco dos jogos nas relações entre as pessoas e, por meio do jogo, compreendem a vida social dos adultos, interiorizando as funções sociais e as regras que são necessárias para estabelecer as relações sociais de um adulto. As crianças de cinco a seis anos, no jogo simbólico, buscam respeitar as regras do papel que estão representando, assim como na realidade, por meio de argumentos para que seu papel no jogo aconteça de fato como é na realidade (ELKONIN, 2009).

O jogo contribui para o desenvolvimento da criança porque quando ela brinca, concentra-se melhor, lembra-se das ações e cria argumentos para interpretar seu papel. É necessário se expressar; ○ que atua positivamente para o desenvolvimento da linguagem comunicativa. No jogo, a criança desenvolve a imaginação, pois aprende a interpretar papéis e substituir objetos por outros significados, contribuindo também para a formação de sua personalidade, porque compreende o comportamento e as relações sociais de um adulto.

\footnotetext{
${ }^{4}$ No livro psicologia do jogo (ELKONIN, 2009), quando traduzido para português foi utilizado o termo jogo protagonizado, no entanto, acreditamos que para a teoria histórico-cultural, o termo que define melhor este conceito seja, jogo de papéis, que será utilizado no decorrer deste trabalho. A palavra 'protagonizado' remete ao significado de personagem principal, e no jogo de papéis todos os envolvidos são importantes.
}

Olhar de professor, Ponta Grossa, v. 24, p. I-22, e-17637.08I, 2021.

Disponível em <https://revistas2.uepg.br/index.php/olhardeprofessor> 
Os jogos de papéis acontecem pela interpretação de papéis que as crianças exercem na brincadeira, e quanto mais idade a criança tem, mais ela irá buscar perfeição na interpretação de seu papel.

$\mathrm{Na}$ brincadeira, a criança utiliza objetos, brinquedos que podem ou não ter semelhança com o objeto real, e, dependendo das possibilidades de sua representação, a atividade da criança no jogo pode representar diversas ações de seu cotidiano e de suas relações sociais.

No jogo de papéis, a criança produz outra imagem, podendo ser os jogos de encenação quando utiliza brinquedos para atuar ou quando ela mesma interpreta um personagem.

As crianças da pré-escola, em suas brincadeiras, preferem representar eventos sociais, atitudes referentes à sua vida cotidiana, e buscam nos objetos (brinquedos) que utilizam uma correspondência entre o desejado e a realidade, como é colocado:

No começo, o jogo consta de ações domésticas executadas por crianças; cozinhar, lavar, carregar de um lado para o outro (três a quatro). Aparecem depois as significações histriônicas relacionadas com estas ou aquelas ações; eu sou a mamãe, eu sou a cozinheira, eu sou o motorista. Ao lado das ações protagonizadas, aparecem nessas significações, as relações entre os personagens e, por último, o jogo culmina com o aparecimento do papel, com a particularidade de que a criança o interpreta num plano duplo: pelo brinquedo e por si mesma (ELKONIN, 2009, p. 238).

O conteúdo real dos jogos são as ações que as crianças realizam com os brinquedos em que se atribui sentido, sendo fundamental que nos jogos tenha uma interpretação que é reconstituída na situação imaginária.

Quando a criança interpreta um papel no jogo de papéis, ela busca de forma determinada conservar sua atuação e a situação imaginária, os brinquedos auxiliam nas ações da criança porque representam o sentido humano de sua utilização.

As crianças com faixa etária de cinco anos já conseguem denominar com outro nome os objetos que são utilizados na brincadeira, de acordo com a função que desempenhará no jogo, assim como interpreta outros papéis; ela pode ser a professora, a mãe, o motorista, entre outros, captando as ações, ocupações e traços característicos do papel que está exercendo.

[...] o sentido do jogo muda para as crianças dos diferentes grupos de idade. Para as mais novas, o sentido está nas ações da pessoa cujo papel interpretam; para as de idade mediana, nas relações dessa pessoa com os outros; e para as mais velhas, nas relações típicas da pessoa cujo papel representam (ELKONIN, 2009, p. 284).

Nos jogos de papéis cada interpretação é claramente definida, a criança estabelece uma linha de conduta, e a fala tem um caráter teatral que é determinado pelo papel que está representando.

$\mathrm{Na}$ idade de três a cinco anos, o principal conteúdo do jogo de papéis são as ações com objetos, as relações sociais que correspondem à lógica das ações reais. $O$ jogo de papéis se diferencia 
da brincadeira quando a criança passa a interpretar as relações sociais, e não apenas manipular os brinquedos, ficando somente na relação entre objetos; a criança começa a interpretar e estabelecer relações sociais pelo jogo de papéis (MELLO, 20I8).

O jogo não é um mundo de fantasia, existem regras que são reflexos das relações reais que a criança vivencia, é a relação existente entre as pessoas e os objetos, pois entre a criança e seu papel está a realidade. No jogo de papéis a criança é capaz de assimilar e reconstituir de forma simbólica as regras sociais de sua cultura.

Pode-se concluir que o jogo de papéis não é apenas uma invenção que as crianças criam de forma inata, mas sim uma reconstituição original das experiências e vivências que ela possui. E cada vez mais, no jogo de papéis, a criança desenvolve a sua consciência, contribuindo para o desenvolvimento das funções psicológicas superiores. $O$ jogo de papéis e o desenho fazem parte do universo infantil, por isso é importante compreender que o desenho assim como o jogo também contribui para o desenvolvimento psíquico da criança.

O desenho - enquanto linguagem - é constituído por um sistema de signos que designam palavras, conceitos, relações, gestos, acontecimentos (cenas), os quais, por sua vez, são signos das relações e entidades reais; dizem respeito ao mundo da vida infantil; simbolizam as entidades reais e as relações entre elas, e são, por isso, carregados de expressões das sensações, emoções, sentimentos e valores, isto é, carregados de sentidos. Os desenhos comunicam, além de estados emocionais e sentimentos, conceitos e valores que as crianças construíram em relação a determinados objetos, pessoas ou acontecimentos (LONGO, NARITA, 20I8, p.4).

O brincar e o desenho infantil são especificidades da criança, por isso é importante que o professor tenha intencionalidade ao possibilitar vivências que permitam as crianças se expressarem pelo brincar e desenhar, tendo um papel fundamental no cotidiano da educação infantil, pois ambos contribuem para o processo de significação e desenvolvimento da imaginação da criança. Além disso, o professor, ao explorar intencionalmente com a criança a possibilidade da representação e imaginação pelo desenho e o brincar, oportuniza o desenvolvimento de linguagens na constituição das funções psíquicas superiores.

\section{Apresentação e discussão sobre os resultados da pesquisa de campo}

A criança fala: o desenho infantil

Em pesquisas científicas do campo da educação é muito comum encontrar a opinião dos adultos sobre as brincadeiras, entretanto este estudo qualitativo buscou justamente romper com o olhar adultocêntrico e trazer a opinião das crianças sobre o brincar. Para isso apresentamos abaixo 
alguns recortes das falas e também produções de desenhos das crianças para representar suas brincadeiras preferidas.

A linguagem pelo desenho deve ser considerada como uma fonte de criação e expressão artística das crianças, tendo em vista que elas se expressam por diferentes linguagens.

Durante a pesquisa de campo surgiram nas narrativas das crianças, nas entrevistas individuais, nas rodas de conversas, nos desenhos e nas observações, as brincadeiras que a abordagem históricocultural classifica como jogos de regras, como pique-pega, esconde-esconde, futebol, basquete, pulapula, em que as regras são explícitas, e seu grau de condicionalidade é cada vez maior (ROCHA, 2005).

$\mathrm{Na}$ entrevista individual de Henrique (5 anos), pôde-se analisar a preferência por jogos com regras, presentes em sua narrativa, entre os turnos 6 e 10.

Entrevista individual- Henrique, 5 anos.

(5) Pesquisadora: Gostaria de saber qual é sua brincadeira preferida?

(6) Henrique: Pega-pega.

(9) Pesquisadora: Quando você está em sua casa o que gosta de brincar?

(10) Henrique: Pique-esconde com os amigos.

$\mathrm{Na}$ entrevista individual, vê-se que aparecem como brincadeiras preferidas os jogos com regras: pega-pega e pique-esconde. Brincadeiras que já têm regras explícitas, conhecidas pelos colegas e muito vivenciadas nesta faixa etária.

A seguir, será apresentado o registro da produção de desenho, na figura I, realizado pela mesma criança, Henrique (5 anos), também de sua brincadeira preferida que é pique-pega. Atentem para os detalhes que a criança traz no desenho. Representou duas figuras humanas sendo que uma encosta a mão na outra. É regra da brincadeira de pique-pega que uma criança tem que encostar na outra para considerar que foi pega; na produção do desenho do Henrique, podemos observar os detalhes e riqueza ao representar a regra da brincadeira de pique-pega de um encostar no outro. Quando o desenho é considerado no cotidiano da Educação Infantil como uma linguagem de expressão artística, o professor amplia as possibilidades de escuta da criança. 
A criança fala: o desenho como fonte de escuta e produção artística sobre as brincadeiras...

Figura I: Desenho realizado por Henrique (5 anos)

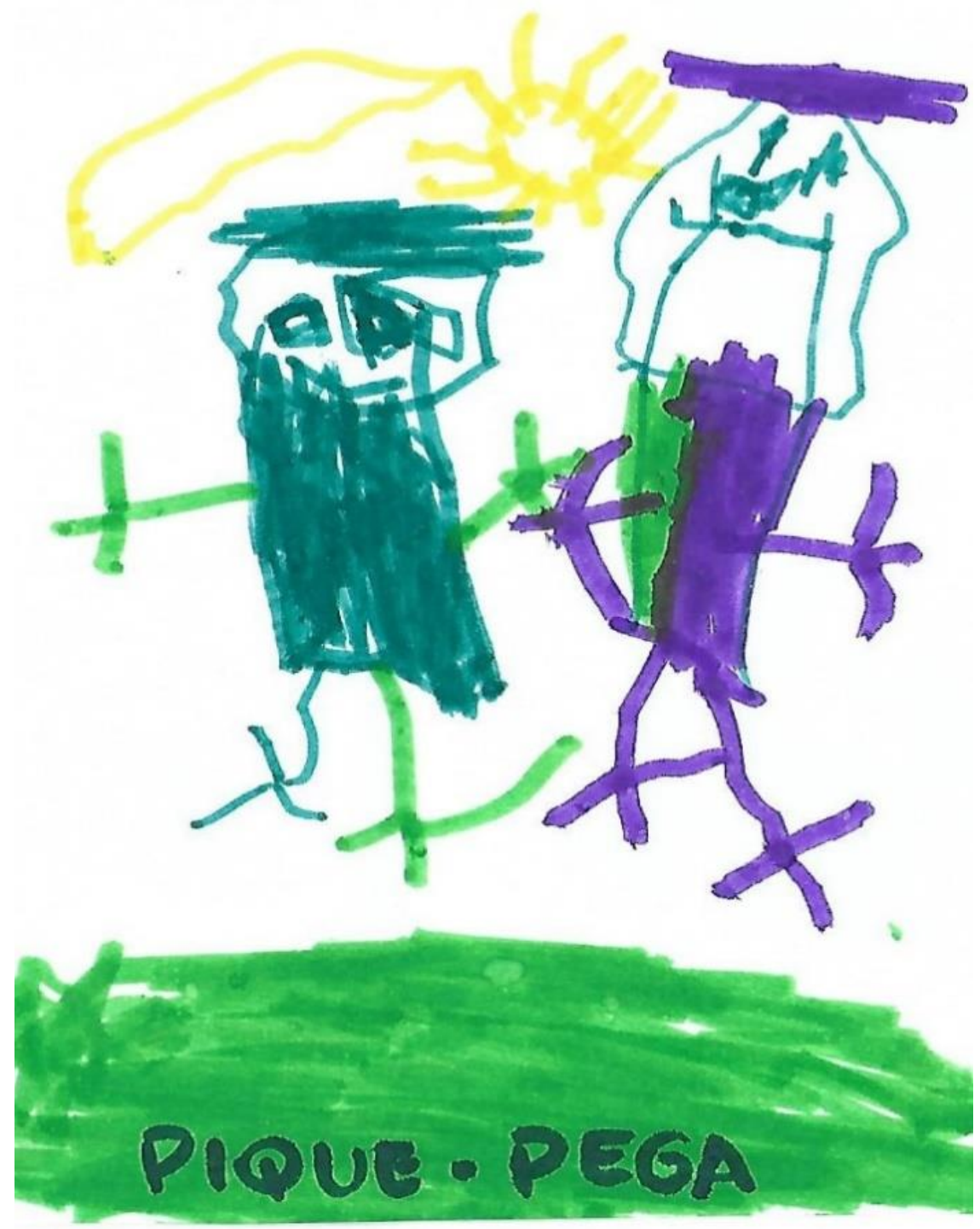

Fonte: Autora, 2018.

$\mathrm{Na}$ figura 2, observa-se o que Raul registrou sobre sua brincadeira preferida, o jogar bola: desenhou uma trave de gol com uma pessoa e a bola na frente desta trave, dando a noção de "diferentes planos" e "profundidade". Desenhou objetos pelo seu conhecimento sobre o que fazia parte da brincadeira, representando o que sabia do jogar bola; também pode-se notar que a criança organizou os objetos no espaço, considerando suas posições, distâncias e proporções a partir de uma base de referência. 
Figura 2: Desenho realizado por Raul (4 anos)

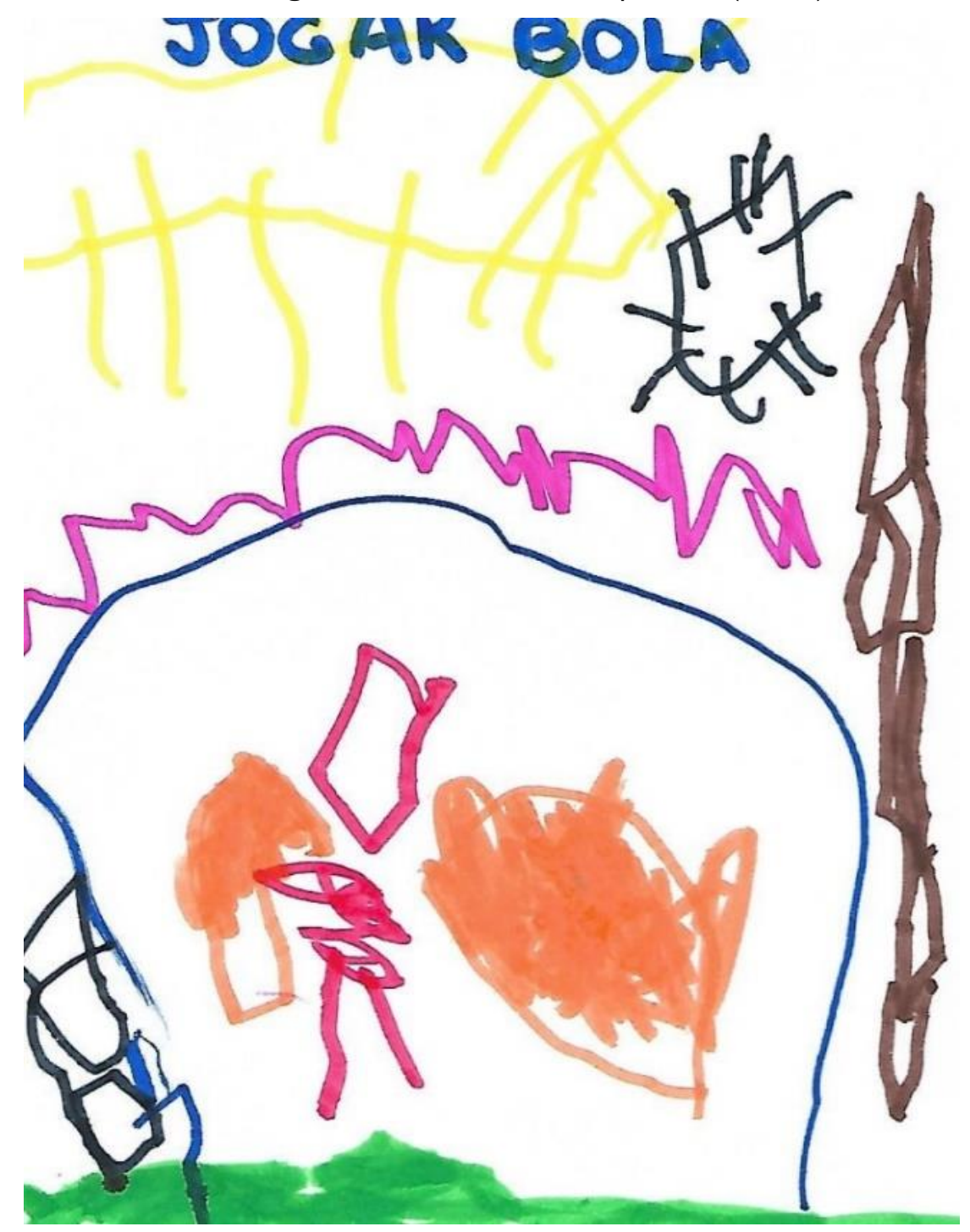

Fonte: Autora, 2018.

Os jogos com regras são pontuados pela perspectiva histórico-cultural como as brincadeiras com regras explícitas, como representado no desenho do Raul (4 anos), o jogo de futebol. São brincadeiras que geralmente necessitam de um grupo de pessoas para que aconteçam, as regras são explícitas e quando não são conhecidas por todos, podem ser combinadas entre os sujeitos que estão envolvidos na brincadeira. No caso do futebol, são regras que foram constituídas culturalmente, é um jogo que o homem em sua história foi elaborando e refazendo, e aperfeiçoando as regras. Nesse ponto se vê como a história do homem social também interfere diretamente, não apenas nas brincadeiras, mas no desenvolvimento da criança, que por meio da brincadeira vai vivenciando e interagindo com o contexto cultural em que está inserida. 
A criança fala: o desenho como fonte de escuta e produção artística sobre as brincadeiras...

O desenho produzido por Luiz (4 anos) também foi para representar o jogo de futebol como sua brincadeira preferida, colocando objetos que são presentes no jogo como a bola e a trave.

Figura 3: Desenho realizado por Luiz (4 anos)

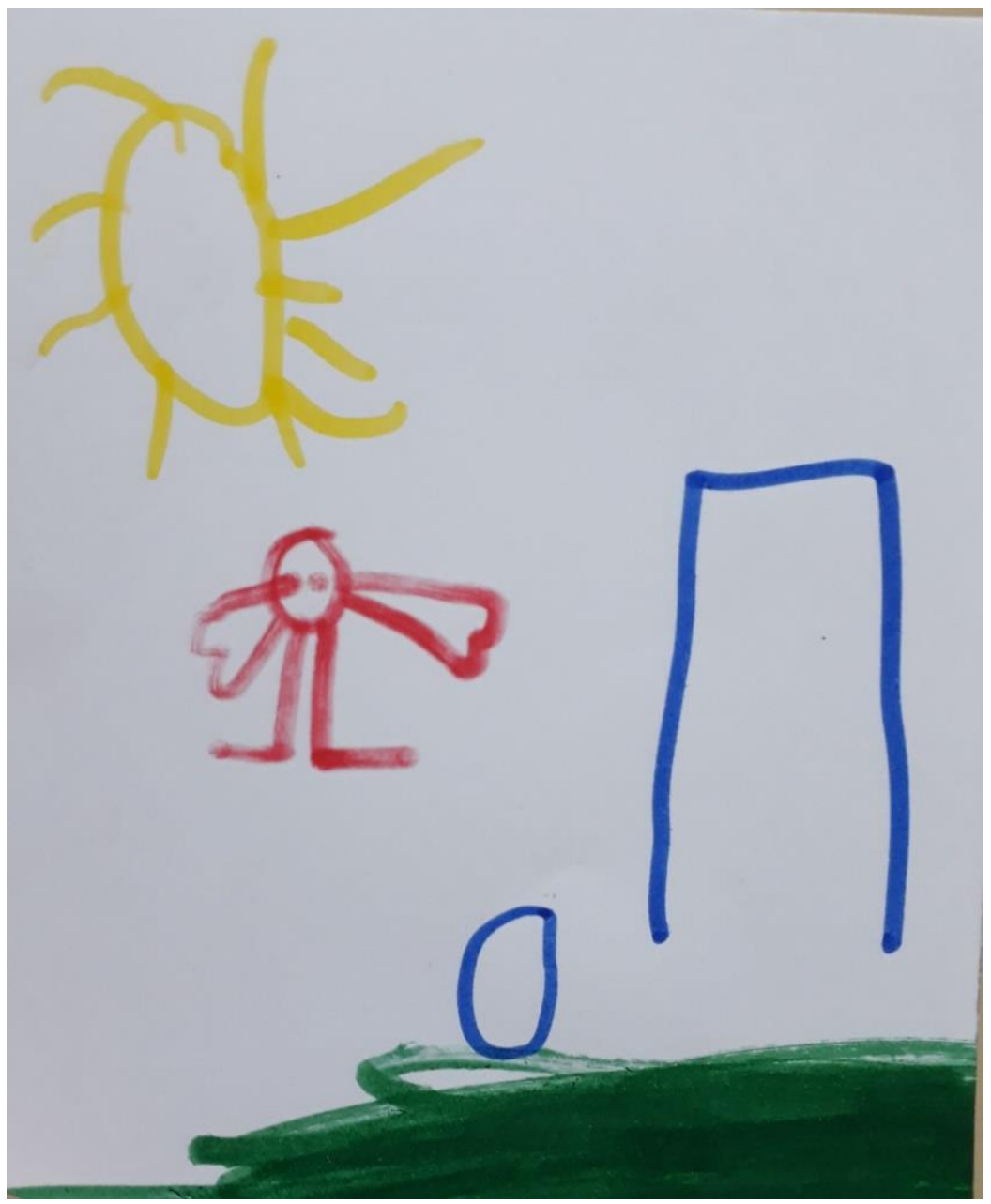

Fonte: Autora, 2018

A criança vai reproduzir aquilo que ela vê ou é feito, porque aprende com o externo - o processo de aprendizagem é um processo de apropriação - o que está diretamente ligado com o seu contexto.

É valido ressaltar a importância da intencionalidade pedagógica do professor ao organizar vivências a partir da escuta atenta das crianças. Neste caso, houve uma relação com a proposta da pesquisadora feita a partir da escuta das brincadeiras preferidas da criança, com a elaboração do desenho e depois a vivência da brincadeira preferida da turma.

Dentro desta proposta pedagógica intencional a partir das brincadeiras, do processo de votação da brincadeira preferida e da representação por meio do desenho, pode-se definir que o desenho e a oralidade estavam inter-relacionados. E neste sentindo, o desenho atua como uma 
linguagem de representação, de significação para a compreensão do outro, bem como da possibilidade de a criança se expressar.

Vigotski (2009) explica que se pode construir um conceito sem vivenciá-lo de forma concreta, mas pela experiência alheia. No desenvolvimento da criança, ela pode aprender com o outro (adulto ou criança) sem vivenciar, de fato, uma experiência, sendo a imaginação e a linguagem que possibilitam essa forma de aprendizagem, em que os seres humanos reelaboram diferentes experiências que existem na história da humanidade, descritas pelo autor como heranças históricas.

\begin{abstract}
Qualquer inventor, mesmo um gênio, é sempre um fruto de seu tempo e de seu meio. Sua criação surge de necessidades que foram criadas antes dele e, igualmente, apoia-se em possibilidades que existem além dele. Eis porque percebemos uma coerência rigorosa no desenvolvimento histórico da técnica e da ciência. Nenhuma invenção ou descoberta científica pode emergir antes que aconteçam as condições materiais e psicológicas necessárias para seu surgimento. A criação é um processo de herança histórica e cada forma que sucede é determinada pelas anteriores (VIGOTSKI, 2009, p.42).
\end{abstract}

As brincadeiras de pique-pega e jogo de futebol podem ser consideradas brincadeiras que fazem parte da herança cultural que já foi vivenciada por outros seres humanos em diferentes épocas. $\mathrm{Na}$ interação com o outro, as heranças culturais vão sendo repassadas para as próximas gerações e reelaboradas pela imaginação, por isso podemos afirmar que a criança também aprende com a experiência de seus pares. Na citação acima, Vigotski apresenta como exemplo as invenções científicas que surgem da necessidade que foram criadas antes delas. Trazemos essa mesma reflexão para as brincadeiras que acontecem no cotidiano da educação infantil, brincadeiras que foram culturalmente constituídas bem como suas regras, que as crianças vão se apropriando, pelo outro e pela imaginação.

A partir das produções artísticas das crianças, pela linguagem oral e linguagem pelo desenho, ampliamos a possibilidade de escuta atenta, pois como vimos, o desenho infantil associado à fala pode dizer muito mais do que os adultos imaginam, rompendo assim com o olhar adultocêntrico, ainda presente em nossa sociedade.

\title{
Conclusões
}

Como se pode ver, o desenho infantil também é uma forma de a criança representar a cultura em que está inserida. $O$ desenho, para além de uma produção artística da criança e forma de escuta, também é uma linguagem da cultura humana, de acordo com a teoria histórico-cultural e contribui para o desenvolvimento das linguagens oral e escrita. Pelo desenho, a criança representa sua oralidade, e os seus traços ganham significado pela própria oralidade e, futuramente, contribui para a compreensão da linguagem escrita; assim, a criança vai se apropriando das funções dos signos de sua cultura, que tem uma função representativa (campo das ideias). 
A criança fala: o desenho como fonte de escuta e produção artística sobre as brincadeiras...

Concordamos com a autora Gobbi (1999, p.139), que analisa desenhos infantis e conclui que "os desenhos são verdadeiros documentos produzidos pelas crianças e com base neles é possível conhecer muito de sua realidade vivida e perceber as crianças como falantes".

O desenho infantil é definido como uma linguagem que permite às crianças experimentar e inventar ideias, ações, vivenciar seus desejos e seus sentimentos expressos de formas variadas pelo seu imaginário. "Ao rabiscar, a criança desenvolve seus processos criativos, ampliando suas potencialidades de expressão" (PILLOTTO; SILVA; MOGNOL, 2007, p.3).

Por isso é fundamental que cada vez mais pesquisadores e professores, ao olhar para o cotidiano da Educação Infantil, tenham a sensibilidade de trazer à tona as diferentes formas de linguagens da criança como fonte de produção artística e cultural.

Também foi ressaltada nesse estudo, a importância da escuta atenta das crianças no cotidiano da Educação Infantil, na construção coletiva de um espaço intencional para prover com ênfase a participação da criança em seu processo de desenvolvimento, e que as mesmas devem ser consideradas capazes e participativas.

No desenvolvimento infantil, a brincadeira, por meio da situação imaginária, contribui de forma efetiva para a apropriação das funções psíquicas superiores e, juntamente com a produção criadora dos desenhos pela criança, é essencial para seu desenvolvimento.

\section{Referências}

DEMARTINI, Z. B. F. Infância, pesquisa e relatos orais. In: FARIA, A. L. G.; DEMARTINI, Z. B. F.; PRADO, P. D. (orgs.) Por uma cultura da infância: metodologias de pesquisas com crianças. Campinas: Autores Associados, 6.Ed., 2007. p. 19-50.

EDWARDS, C.; GANDINI, L.; FORMAN, G. As cem linguagens da criança: a abordagem de Reggio Emília na Educação da primeira infância. Porto Alegre: Penso, 2016.

ELKONIN, D. B. Psicologia do jogo. São Paulo: Martins Fontes, 2009.

FERREIRA, S. Imaginação e linguagem no desenho da criança. Campinas: Papirus, 1998.

FONTANA, R.; CRUZ, N. Psicologia e trabalho pedagógico. São Paulo: Atual, 1997.

FRANCO, R. R. A fundamentação jurídica do direito de brincar. 2008. 253f. Dissertação (Mestrado em Educação). Universidade Estadual de Londrina, Londrina, 2008.

GOBBI, M. Lápis vermelho é de mulherzinha: Desenho infantil, relações de gênero e crianças pequenas. Pró-posições. Vol. I0, no. I, março de 1999. Disponível em: https://www.fe.unicamp.br/pffe/publicacao//999/28-artigos-gobbim.pdf. Acesso em 2 de junho de 2019.

IAVELBERG, R. O desenho cultivado da criança. Porto Alegre: Editora Zouk, 2013.

Olhar de professor, Ponta Grossa, v. 24, p. I-22, e-I7637.08I, 2021.

Disponível em <https://revistas2.uepg.br/index.php/olhardeprofessor> 
LEONTIEV, A. N. Os princípios psicológicos da brincadeira pré-escolar. IN: VIGOTSKII, L.S.; LURIA, A. R.; LEONTIEV, A. N. Linguagem, desenvolvimento e aprendizagem. 6 ed. São Paulo: Ícone editora, 2010. p. II9-142.

LONGO, C. S. NARITA, S. Psicologia do desenho infantil: uma proposta na perspectiva históricocultural. Rev. Psicologia.pt. p. I-I I, 2018. Disponível em:

https://www.psicologia.pt/artigos/ver_artigo.php?psicologia-do-desenho-infantil-uma-proposta-naperspectiva-historico-cultural\&codigo=AI272\&area=dI0. Acesso em I3 de mar. de 2021 .

MELLO, M. A. Diferenças conceituais e pedagógicas entre brincadeira e jogo na teoria histórico-cultural: implicações no ensino e na aprendizagem na educação infantil. Tese (Acadêmica Inédita). UFSCAR: São Carlos, 2018.

MINAYO, M. C. S. Análise qualitativa: teoria, passos e fidedignidade. Cienc. Saúde Coletiva, v. 17, n.3, p.62I-625, 2012.

MOURA, E. A.; MATA, M. S.; PAULINO, P. R.V.; FREITAS, A. P.; JUNIOR, C. A. M.; MÁRMORA, C. $\mathrm{H}$. C. Os planos genéticos do desenvolvimento humano: A contribuição de Vigotski. Revista de ciências humana de Unitau. Vol. 10, n. I, p. I06-I I4, 20I6. Disponível em:

http://www.rchunitau.com.br/index.php/rch/article/view/298. Acesso em 0 I de jun. de 2018.

NATIVIDADE, M. R. COUTINHO, M. C. ZANELLA, A. V. Desenho na pesquisa com crianças: análise na perspectiva histórico-cultural. Rev. Contextos Clínicos. p. 9-18, 2008. Disponível em: http://pepsic.bvsalud.org/scielo.php?script=sci_abstract\&pid=S1983-

$34822008000100002 \&$ lng=pt\&nrm=iso. Acesso em I 3 de mar. de 2021 .

PILLOTTO, S. S. D.; SILVA, M. K.; MOGNOL, L. T. Grafismo infantil: linguagem do desenho. UDESC, 2007. Disponível em: http://revistas.udesc.br/index.php/linhas/article/viewFile//219//033. Acesso em 02 de junho de 2019.

ROCHA, M. S. P. M. L. Não brinco mais: a (des)construção do brincar no cotidiano educacional. ljuí: Ed. Unijuí, 2005.

SILVA, S. M. C. A constituição social do desenho da criança. Campinas: Mercado das letras, 2002.

SILVA, M. C. S. Condições sociais da constituição do desenho infantil. Psicol. USP. 1998, v.9, n.2, p. 205-220. Disponível em: http://dx.doi.org//0.1590/S0103-6564/998000200008. Acesso em 06 de abril de 2019.

SILVA, P. R.; SOUZA, F. C.; OLIVEIRA, R. C. D. Os direitos das crianças pequenas: do silêncio ao grito. In: SANTOS, M. W.; TOMAZZETTI, C. M.; MELLO, S. A. (orgs.) Eu ainda sou criança: educação infantil e resistência. São Carlos: EdUFSCar, 20I8. p. 8I-90.

VIGOTSKI, L. S. A formação social da mente: o desenvolvimento dos processos psicológicos superiores. São Paulo: Martins Fontes, 2007.

VIGOTSKI, L. S. Imaginação e criação na infância. São Paulo: Ática, 2009.

VIGOTSKI, L. S. Psicologia pedagógica. São Paulo: WMF Martins Fontes, 2010.

Olhar de professor, Ponta Grossa, v. 24, p. I-22, e-17637.08I, 2021.

Disponível em <https://revistas2.uepg.br/index.php/olhardeprofessor> 
Recebido em: I5 de março de 202I.

Versão corrigida recebida em: 23 de maio de 2021 .

Aceito em: 15 de agosto de 2021 .

Publicado online em: 03 de setembro de 2021.

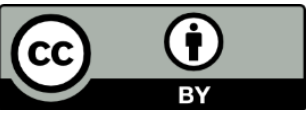

